\title{
Sequences of Complementary DNAs That Encode the NA1 and NA2 Forms of Fc Receptor III on Human Neutrophils
}

\author{
Peter A. Ory, Marcus R. Clark, Ely E. Kwoh, Sarah B. Clarkson, and Ira M. Goldstein \\ Rosalind Russell Arthritis Research Laboratory, Department of Medicine, University of California, San Francisco; \\ and the Medical Service, San Francisco General Hospital, San Francisco, California 94143-0868
}

\begin{abstract}
Two polymorphic forms of Fc receptor III (FcR III) are expressed on human neutrophils. These differ with respect to their apparent molecular masses after digestion with $\mathrm{N}$-glycanase, and with respect to their reactivity with MAb Gran 11 and alloantisera which recognize determinants (NA1 and NA2) of the biallelic neutrophil antigen (NA) system. To determine the molecular basis for this polymorphism we isolated RNA from neutrophils of NA1NA1 and NA2NA2 homozygotes and synthesized corresponding cDNAs. cDNAs encoding FcR III were then amplified using the polymerase chain reaction, cloned, and sequenced. The cDNA that encodes FcR III on NA1NA1 neutrophils differed from the cDNA that encodes FcR III on NA2NA2 neutrophils at five nucleotides, predicting four amino acid substitutions. As a result, NA1 FcR III has only four potential $\boldsymbol{N}$-linked glycosylation sites as compared with six in NA2 FcR III. The amino acid substitutions and differences in the number of potential $\boldsymbol{N}$-linked glycosylation sites probably account for the different forms of neutrophil FcR III observed after digestion with $\boldsymbol{N}$-glycanase and for the antigenic heterogeneity of this receptor.
\end{abstract}

\section{Introduction}

Receptors on human cells for the Fc regions of IgG immunoglobulins (FcR) ${ }^{1}$ mediate phagocytosis of IgG-coated particles as well as other responses to encounters with antigen-antibody complexes $(1,2)$. One of these receptors, FcR III, is expressed on the surfaces of neutrophils, eosinophils, tissue macrophages, natural killer (NK) cells, and a small subset of T lymphocytes (1-5). FcR III on human neutrophils is extensively glycosylated (5-7) and polymorphic (8). After immunoprecipitation from surface-labeled cells of healthy donors and treatment with $N$-glycanase, neutrophil FcR III appears after SDS-

Address all correspondence to Dr. Ira M. Goldstein, Department of Medicine, Box 0868, University of California, San Francisco, CA 94143-0868.

Received for publication 6 February 1989 and in revised form 11 August 1989.

1. Abbreviations used in this paper: FcR, Fc receptor(s); NA, neutrophil antigen; NK, natural killer; PCR, polymerase chain reaction.

J. Clin. Invest.

(c) The American Society for Clinical Investigation, Inc.

$0021-9738 / 89 / 11 / 1688 / 04 \$ 2.00$

Volume 84, November 1989, 1688-1691
PAGE as either a single $29-\mathrm{kD}$ band, a single $33-\mathrm{kD}$ band, or a combination of 29- and 33-kD bands (8). These forms of neutrophil FcR III also differ with respect to their reactivity with anti-FcR III MAbs as well as with alloantisera that recognize determinants of the biallelic neutrophil antigen (NA) system (8). Whereas neutrophils from all individuals are recognized by the anti-FcR III MAb 3G8, only neutrophils that yield the 29-kD band react with MAb Gran 11 and anti-NA1 alloantibodies. Neutrophils that yield the $33-\mathrm{kD}$ band are recognized by anti-NA 2 alloantibodies.

To determine the molecular basis for the polymorphism involving FcR III, we isolated RNA from neutrophils of NA1NA1 and NA2NA2 homozygotes and synthesized corresponding cDNAs. cDNAs encoding FcR III were then amplified using the polymerase chain reaction (PCR; 9), cloned, and sequenced. The coding sequences of the cDNAs isolated from NA1NA1 and NA2NA2 neutrophils differed at five bases, and were found to be identical with the coding sequence of FcR III cDNAs that had been isolated previously from human PBMC (10) and human placenta (11), respectively.

\section{Methods}

MAbs and alloantisera. The cell line producing MAb 3G8 (murine $\mathrm{IgG}_{1} ; 3$ ) and ascites containing MAb Gran 11 (murine $\mathrm{IgG}_{2 a} ; 12$ ) were provided by Dr. David Segal (National Institutes of Health [NIH], Bethesda, MD) and Dr. Pedro A. T. Tetteroo (Central Laboratory of the Netherlands Red Cross, Amsterdam, The Netherlands), respectively. Polyclonal anti-NA1 and anti-NA2 alloantisera (13) were provided by Dr. Parviz Lalezari (Albert Einstein Medical Center, Bronx, NY).

Immunoassays. Leukocyte suspensions containing > 95\% neutrophils were prepared from venous blood of healthy adult volunteers by centrifugation on Ficoll-Hypaque and sedimentation with dextran (14). Neutrophils were fixed with $1.0 \%$ (wt/vol) paraformaldehyde, washed with PBS, and incubated for $30 \mathrm{~min}$ at $4^{\circ} \mathrm{C}$ with either MAb 3G8 $(10 \mu \mathrm{g} / \mathrm{ml})$, MAb Gran 11 ascites (1:1,000 dilution), or anti-NA alloantisera (undiluted). Normal human serum (undiluted) and the

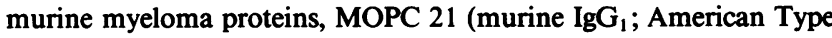
Culture Collection, Bethesda, MD) and RPC 5 (murine $\operatorname{~IgG~}_{2 a}$; Bionetics Laboratory Products, Kensington, MD), were used as controls. Cells were washed and then incubated with either FITC-conjugated goat anti-human IgG, IgM, and IgA or FITC-conjugated goat antimouse IgG (Jackson Immuno Research Laboratories Inc., Avondale, PA). Neutrophils finally were examined by fluorescence microscopy and/or flow cytometry using a FACS IV (Becton Dickinson Immunocytometry Systems, Mountain View, CA).

Isolation of RNA. RNA was isolated from neutrophils $\left(5-7 \times 10^{8}\right.$ cells) of an NA1NA1 homozygote and two NA2NA2 homozygotes using a minor modification of a method described previously (15). Briefly, cells were pelleted by centrifugation and lysed (while vortex- 
ing) with $3.3 \mathrm{ml}$ of a solution containing $5.0 \mathrm{M}$ guanidine isothiocyanate, $50 \mathrm{mM}$ TrisCl, $10 \mathrm{mM}$ EDTA, and $8.0 \%$ (vol/vol) 2-mercaptoethanol. The lysate was aspirated repeatedly through a 19-g needle, mixed with $1.3 \mathrm{~g} \mathrm{CsCl}$, and layered over a cushion of $5.7 \mathrm{M} \mathrm{CsCl}$. After centrifugation overnight at $120,000 \mathrm{~g}$, pelleted RNA was dissolved in $10 \mathrm{mM}$ TrisCl containing $1.0 \mathrm{mM}$ EDTA and $1.0 \%$ (vol/vol) SDS, extracted with butanol/chloroform (1:4), and precipitated with ethanol. Precipitated RNA was redissolved in deionized water containing $1,000 \mathrm{U} / \mathrm{ml}$ placental RNase inhibitor (Pharmacia LKB Biotechnology, Inc., Piscataway, NJ).

Northern blot analysis. RNA $(25 \mu \mathrm{g})$ isolated from neutrophils of an NA2NA2 homozygote was electrophoresed on a $1.0 \%$ (wt/vol) agarose gel containing $2.2 \mathrm{M}$ formaldehyde and then blotted onto a nylon membrane (GeneScreen Plus; New England Nuclear, Boston, MA). Prehybridization and hybridization were carried out as described previously (16), using a 546-bp fragment of the FcR III cDNA isolated from human placenta (11; provided by Dr. Brian Seed, Massachusetts General Hospital, Boston, MA).

Synthesis and amplification of cDNAs. cDNA-mRNA hybrids were synthesized by the method of Gubler and Hoffman (17), using $<10 \mu \mathrm{g}$ of neutrophil RNA, primer B (Table I), and a COPY KIT from Invitrogen (San Diego, CA). Oligonucleotide primers A and B (Biomolecular Resource Center, University of California, San Francisco, CA) were complementary to 5'-and 3'-untranslated regions (bases 1-21 and bases $805-825$, respectively) flanking the coding sequence (bases 34-732) of the FcR III cDNA isolated from human placenta (11), and contained nonhomologous bases at their 5 '-ends to create recognition sites for the restriction enzymes, Eco RI and Hind III (Table I). The PCR was performed as described previously (9), using a GeneAmp DNA amplification reagent kit (Perkin-Elmer Cetus, Norwalk, CT), $100 \%$ of the neutrophil cDNA-mRNA hybrids, $0.1 \mu \mathrm{mol}$ each of primers $\mathrm{A}$ and $\mathrm{B}$, and $2.5 \mathrm{U}$ Taq DNA polymerase. Reaction mixtures were subjected to 40 cycles of denaturation $\left(94^{\circ} \mathrm{C}\right.$ for $\left.2 \mathrm{~min}\right)$, annealing $\left(55^{\circ} \mathrm{C}\right.$ for $\left.2 \mathrm{~min}\right)$, and extension $\left(72^{\circ} \mathrm{C}\right.$ for $\left.5 \mathrm{~min}\right)$ in a DNA thermal cycler (Perkin-Elmer Cetus).

Cloning and sequencing of amplified cDNAs. Amplified cDNAs were digested with Eco RI and Hind III (New England Biolabs, Beverly, MA), electrophoresed on 5\% polyacrylamide gels, electroeluted, and cloned into pUC118 and pUC119 plasmids (provided by Dr. Dennis Henner, Genentech, Inc., South San Francisco, CA). Singlestranded templates were prepared using the helper phage, M13K07 (18), and sequenced by the dideoxynucleotide chain-termination method (19) using modified T7 DNA polymerase (United States Biochemical Corp., Cleveland, $\mathrm{OH}$ ).

\section{Results}

Identification of NA1NA1 and NA2NA2 homozygotes. Healthy volunteer blood donors were identified as either NA1NA1 or NA2NA2 homozygotes by examining reactivity of isolated neutrophils with MAbs 3 G8 and Gran 11, and with anti-NA1 and anti-NA2 alloantisera. As summarized in Table II, neutrophils from donor 1 were recognized by MAb 3G8, MAB Gran 11 , and anti-NA1 alloantibodies, but not anti-NA2 alloantibodies. Donor 1, therefore, is an NA1NA1 homozygote. Neutrophils from donors 2 and 3, on the other hand, reacted with MAb 3G8 and anti-NA2 alloantibodies, but not with anti-

Table I. Synthetic Oligonucleotide Primers

\section{Primer A: 5' AGAGAATTCTCTTTGGTGACTTGTCCACTC $3^{\prime}$} Primer B: $\quad$ 5' AGAAAGCTTGCTCTTATTACTCCCATGGGA 3

Recognition sites for Eco RI (primer A) and Hind III (primer B) are underlined.
Table II. Reactivity of Neutrophils with MAbs and Alloantisera

\begin{tabular}{lcccc}
\hline & MAb 3G8 & MAb Gran 11 & Anti-NA1 & Anti-NA2 \\
\hline Donor 1 & + & + & + & - \\
Donor 2 & + & - & - & + \\
Donor 3 & + & - & - & +
\end{tabular}

,$+>20 \%$ of neutrophils reacted with the antibody;,$-<3 \%$ of neutrophils reacted with the antibody. Cells from each donor were examined on at least three separate occasions.

NA1 alloantibodies or MAb Gran 11. Donors 2 and 3, therefore, are NA2NA2 homozygotes. None of the cells reacted with the control myeloma proteins, MOPC 21, and RPC 5, or with normal human serum (not shown). In studies reported previously (8), FcR III on neutrophils from donor 1 appeared as a single $29-\mathrm{kD}$ band after digestion with $N$-glycanase and SDS-PAGE, while FcR III on neutrophils from donors 2 and 3 appeared as a single $33-\mathrm{kD}$ band.

Northern blotting of neutrophil RNA. Analysis of a Northern blot prepared with RNA from peripheral blood neutrophils of an NA2NA2 homozygote (donor 2) revealed a single $\sim 2$-kb transcript that hybridized with a 546-bp fragment of an FcR III cDNA (11; Fig. 1).

Amplification, cloning, and sequencing of cDNAs. RNA isolated from neutrophils of the NA1NA1 and NA2NA2 homozygotes was used to prepare corresponding cDNAs. These were then amplified using Taq DNA polymerase and synthetic oligonucleotide primers complementary to regions flanking the coding sequence of an FcR III cDNA (11). In each case, 40 cycles of amplification yielded a cDNA fragment of the expected size (843 bp; Fig. 2). After digestion with Eco RI and Hind III these fragments were cloned into pUC plasmids and sequenced.

Analysis of the complete nucleotide sequences of three independent clones of amplified cDNA prepared from RNA of NA1NA1 neutrophils (from donor 1) revealed that they were identical to each other and to the nucleotide sequence of the FcR III cDNA isolated previously from human PBMC (10). Analysis of the nucleotide sequences of independent clones (three from donor 2 and one from donor 3 ) of amplified cDNA prepared from RNA of NA2NA2 neutrophils revealed that they also were identical to each other and to the nucleotide sequence of the FcR III cDNA isolated previously from human placenta (11). NA1 FcR III cDNAs differed from the corresponding NA2 FcR III cDNAs at five codons: AGG vs. AGC at codon 36 ; CTC vs. CTT at codon 38 ; AAC vs. AGC at codon 65; GAC vs. AAC at codon 82; and GTC vs. ATC at codon 106 (Table III). The deduced amino acid sequence of

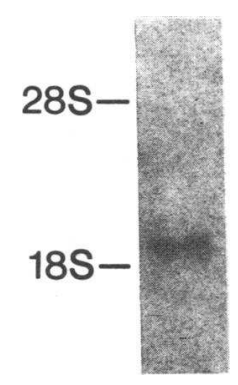

Figure 1. Northern blot analysis of neutrophil RNA. RNA $(25 \mu \mathrm{g})$ isolated from neutrophils of an NA2NA2 homozygote hybridized with a ${ }^{32} \mathrm{P}$ labeled 546-bp fragment of an FcR III cDNA. $18 \mathrm{~S}$ and $28 \mathrm{~S}$ markers are shown. 


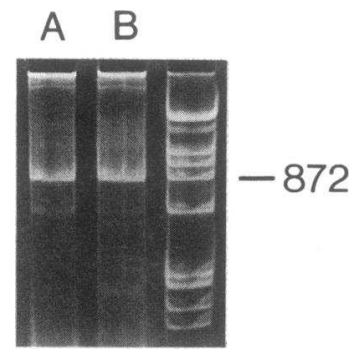

Figure 2. PAGE of amplified FcR III cDNA from an NA2NA2 homozygote $(843 \mathrm{bp})(A)$; and amplified FcR III cDNA from an NA1NA1 homozygote $(B)$. The 872-bp fragment of $\phi$ X174 RF DNA digested with Hae III is shown on the right. Gel was stained with ethidium bromide.

NA1 FcR III differed from that of NA2 FcR III at residues 36 (Arg vs. Ser), 65 (Asn vs. Ser), 82 (Asp vs. Asn), and 106 (Val vs. Ile). These amino acid substitutions result in there being only four potential $N$-linked glycosylation sites in NA1 FcR III as compared with six in NA2 FcR III. It should be noted that since the findings described above were reproducible, and since similar cDNAs were never produced from other templates, it is quite unlikely that they represent artifacts of the PCR.

\section{Discussion}

To determine the molecular basis for the polymorphism involving neutrophil FCR III we used a recently described strategy for amplifying single-stranded cDNAs prepared from small amounts of unfractionated cellular RNA (20). The feasibility of using RNA from peripheral blood neutrophils for our studies was suggested by the recent demonstration that human neutrophils constitutively synthesize FcR III (21), and by the observation reported here that these cells contain mRNA transcripts that hybridize with an FcR III cDNA probe (Fig. 1). Consequently, we isolated RNA from neutrophils of NA1NA1 and NA2NA2 homozygotes and synthesized corresponding cDNA-mRNA hybrids. Sequences encoding the different forms of neutrophil FcR III were then amplified using the PCR (Fig. 2). Directional cloning and sequencing of the amplified cDNAs were facilitated by adding recognition sites for Eco RI and Hind III to the synthetic oligonucleotide primers used in the PCR.

The coding sequence of the cDNA prepared from neutrophil RNA of the NA1NA1 homozygote was identical to the coding sequence of the FCR III cDNA isolated previously from human PBMC (10), while the coding sequences of the cDNAs prepared from neutrophil RNA of the two NA2NA2 homozygotes were identical to the coding sequence of the FCR III cDNA isolated previously from human placenta (11). Each cDNA contain an open reading frame of 699 nucleotides,

Table III. Differences between the Nucleotide Sequences of cDNAs Encoding NAI FcR III and NA2 FcR III and Deduced Amino Acid Sequences

\begin{tabular}{llllll}
\hline & Codon 36 & Codon 38 & Codon 65 & Codon 82 & Codon 106 \\
\hline \multirow{2}{*}{ NA1 FcR III } & AGG & CTC & AAC & GAC & GTC \\
& Arg & Leu & Asn & Asp & Val \\
& & & & & \\
NA2 FcR III & AGC & CTT & AGC & AAC & ATC \\
& Ser & Leu & Ser* & Asn* & Ile \\
& & & & & \\
\hline
\end{tabular}

* Residues in potential $N$-linked glycosylation sites. which would be expected to encode a protein containing 233 amino acid residues. The deduced amino acid sequence of each revealed a putative leader sequence of $\sim 18$ residues, four symmetrically arranged cysteine residues surrounded by Iglike domains, and a 21-residue hydrophobic domain followed by four hydrophilic residues at the carboxy terminus $(10,11)$. The latter is a common feature of proteins that are anchored to cell membranes via glucosyl-phosphatidylinositol linkages (22), and is in accord with the observations that FcR III is readily removed from the surfaces of neutrophils by treatment with phosphatidylinositol-specific phospholipase $C(23,24)$.

As indicated above, the cDNAs that encode NAl FcR III and NA2 FcR III are identical to cDNAs isolated previously from human PBMC and human placenta, respectively (10, 11). However, in neither of the reports describing the isolation of these cDNAs was there any indication that neutrophils of the individuals from whom the PBMC and placental tissue were obtained were examined for reactivity with MAb Gran 11 or with anti-NA alloantisera. Consequently, we can only speculate that the individual from whom the PBMC were obtained was an NA1NA1 homozygote or an NA1NA2 heterozygote, and that the individual from whom the placenta was obtained was an NA2NA2 homozygote or an NA1NA2 heterozygote.

Since placenta and PBMC contain a variety of cell types, it is unknown whether the cDNAs isolated from these sources were derived from neutrophil mRNA. Similarly, although we used highly purified neutrophils as a source of RNA for our studies, and although the RNA contained readily detectable FCR III transcripts (Fig. 1), we cannot exclude the possibility that the transcripts we amplified were derived from cells other than neutrophils. However, evidence appeared while this report was being revised for publication that the gene that encodes neutrophil FcR III is distinct from the gene that encodes NK cell FcR III $(25,26)$. The cDNA that encodes NK cell for FcR III differs from other leukocyte FcR III cDNAs at $>10$ bases. Most importantly, one base-change ( $\mathrm{C}$ for $\mathrm{T}$ at position 733) alters the stop codon (codon 234) in such a way as to increase the length of the open reading frame by an additional 63 bases. This cDNA, therefore, encodes a protein containing an additional 21 amino acids, which would be expected to be anchored to the NK cell via its transmembrane domain. Accordingly, deglycosylated FCR III from NK cells is significantly larger than deglycosylated FcR III from neutrophils (7), and expression of FcR III by NK cells is not affected by treatment with phosphatidylinositol-specific phospholipase $C(24,25)$. Furthermore, using methods very similar to those described in this report, Ravetch and Perussia (26) confirmed that cDNAs that encode the NA1 and NA2 forms of neutrophil FcR III differ at five bases and are products of alleles of a single gene. Thus, the genes that encode FcR III on neutrophils and NK cells are expressed in a cell-specific fashion.

The relationship of the deduced amino acid sequences of the NA1 and NA2 forms of neutrophil FcR III to the structural polymorphism we observed previously (8) is unclear. Specifcally, it is difficult to explain how only four amino acid substitutions could account for the difference in size we observed between the NA1 and NA2 forms of FCR III ( 29 and $33 \mathrm{kD}$, respectively) after SDS-PAGE when the receptors were immunoprecipitated and treated with $N$-glycanase. Since others have observed that exhaustive digestion of neutrophil FcR III with peptide/ $N$-glycosidase $\mathrm{F}$ yields a 25 -kD polypeptide (6), the most likely explanation for the findings we reported pre- 
viously (8) is that $\mathrm{N}$-glycanase did not completely deglycosylate the two forms of the receptor.

In summary, results of the studies described in this report indicate that the NA1 and NA2 forms of FCR III on human neutrophils are products of two different alleles of a single gene. The NA1 FcR III cDNA differed from the NA2 FcR III cDNA at five bases, predicting four amino acid substitutions (Table III). As a result of these substitutions, NA1 FcR III has only four potential $N$-linked glycosylation sites as compared with six in NA2 FcR III. These differences in primary structure and resulting posttranslational modifications probably account for the different forms of FcR III observed after partial digestion with $\mathrm{N}$-glycanase, as well as for the antigenic heterogeneity of this receptor.

\section{Acknowledgments}

The authors thank Drs. Michael McGrath, Donald Payan, and Paul Dazin, as well as Ms. Patricia Lekas, for assistance with flow cytometry. The authors also thank Dr. Gary Peltz for providing us with the sequence of the FcR III cDNA he isolated from human PBMC.

This work was supported in part by grants from the NIH (AR-36949) and the Treadwell Foundation. Dr. Ory and Dr. Clark were supported by an Institutional National Research Service Award (AR-07304).

\section{References}

1. Unkeless, J. C., and S. D. Wright. 1988. Phagocytic cells. Fc and complement receptors. In Inflammation: Basic Principles and Clinical Correlates. J. I. Gallin, I. M. Goldstein, and R. Snyderman, editors. Raven Press, New York. 343-362.

2. Unkeless, J. C. 1989. Function and heterogeneity of human Fc receptors for IgG. J. Clin. Invest. 83:355-361.

3. Fleit, H. B., S. D. Wright, and J. C. Unkeless. 1982. Human neutrophil $\mathrm{Fc} \gamma$ receptor distribution and structure. Proc. Natl. Acad. Sci. USA. 79:3275-3279.

4. Clarkson, S. B., R. P. Kimberly, J. E. Valinsky, M. D. Witmer, J. B. Bussel, R. L. Nachman, and J. C. Unkeless. 1986. Blockade of clearance of immune complexes by an anti-Fc $\gamma$ receptor monoclonal antibody. J. Exp. Med. 164:474-489.

5. Clarkson, S. B., and P. A. Ory. 1988. CD16. Developmentally regulated IgG Fc receptors on cultured human monocytes. J. Exp. Med. 167:408-420.

6. Fleit, H., M. Kuhnle. 1988. Biochemical characterization of an $\mathrm{Fc} \gamma$ receptor purified from human neutrophils. J. Immunol. 140:3120-3125.

7. Lanier, L. L., J. J. Ruitenberg, and J. H. Phillips. 1988. Functional and biochemical analysis of CD16 antigen on natural killer cells and granulocytes. J. Immunol. 141:3478-3485.

8. Ory, P. A., I. M. Goldstein, E. E. Kwoh, and S. B. Clarkson. 1989. Characterization of polymorphic forms of Fc receptor III on human neutrophils. J. Clin. Invest. 83:1676-1681.

9. Saiki, R. K., D. H. Gelfand, S. Stoffel, S. J. Scharf, R. Higuchi, G. T. Horn, K. B. Mullis, and H. A. Erlich. 1988. Primer-directed enzymatic amplification of DNA with a thermostable DNA polymerase. Science (Wash. DC). 239:487-494.

10. Peltz, G. A., H. O. Grundy, R. V. Lebo, H. Yssel, G. S. Barsh, and K. W. Moore. 1989. Human Fc $\gamma$ RIII: Cloning, expression, and identification of an $\mathrm{Fc} \gamma$ receptor chromosomal locus. Proc. Natl. Acad. Sci. USA. 86:1013-1017.

11. Simmons, D., and B. Seed. 1988. The Fc receptor of natural killer cells is a phospholipid-linked membrane protein. Nature (Lond.). 333:568-570.

12. Werner, G., A. E. G. Kr. von dem Borne, M. J. E. Bos, J. F. Tromp, C. M. van der Plas-van Dalen, F. J. Visser, C. P. Engelfreit, and P. A. T. Tetteroo. 1986. Localization of the human NAl alloantigen on neutrophil Fc- $\gamma$-receptors. In Leukocyte Typing II, Vol. 3. Human Myeloid and Hematopoietic Cells. E. L. Reinherz, B. F. Haynes, L. M. Nadler, and I. D. Bernstein, editors. Springer-Verlag, New York. 3:109-121.

13. Lalezari, P. 1984. Granulocyte antigen systems. In Immunohaematology. C. P. Engelfreit, J. J. van Loghem, and A. E. G. Kr. von dem Borne, editors. Elsevier Science Publishers, Amsterdam. 33-44.

14. Boyum, A. 1968. Isolation of mononuclear cells and granulocytes from human blood. Isolation of mononuclear cells by one centrifugation and of granulocytes by combining centrifugation and sedimentation at 1 g. Scand. J. Clin. Lab. Invest. 21 (Suppl 97):77-89.

15. Chrigwin, J. M., A. E. Pryzbyla, R. J. MacDonald, and W. J. Rutter. 1979. Isolation of biologically active RNA from sources enriched in ribonuclease. Biochemistry. 18:5294-5298.

16. Thomas, P. S. 1980. Hybridization of denatured RNA and small DNA fragments transferred to nitrocellulose. Proc. Natl. Acad. Sci. USA. 77:5201-5205.

17. Gubler, U., and B. J. Hoffman, 1983. A simple and very efficient method for generating cDNA libraries. Gene (Amst.). 25:263269.

18. Vieira, J., and J. Messing. 1987. Production of single-stranded plasmid DNA. Methods Enzymol. 153:3-11.

19. Sanger, F., S. Nicklen, and A. R. Coulson. 1977. DNA sequencing with chain-terminating inhibitors. Proc. Natl. Acad. Sci. USA. 74:5463-5467.

20. Newman, P. J., J. Gorski, G. C. White II, S. Gidwitz, C. J. Cretney, and R. H. Aster. 1988. Enzymatic amplification of plateletspecific messenger RNA using the polymerase chain reaction. J. Clin. Invest. 82:739-743.

21. Jack, R. M., and D. T. Fearon. 1988. Selective synthesis of mRNA and proteins by human peripheral blood neutrophils. J. Immunol. 140:4286-4293.

22. Low, M. G. 1987. Biochemistry of the glycosyl-phosphatidylinositol membrane protein anchors. Biochem. J. 244:1-13.

23. Selvaraj, P., W. F. Rosse, R. Silber, and T. A. Springer. 1988. The major Fc receptor in blood has a phosphatidylinositol anchor and is deficient in paroxysmal nocturnal haemoglobinuria. Nature (Lond.). 333:565-567.

24. Huizinga, T. W. J., C. E. van der Schoot, C. Jost, R. Klaassen, M. Kleijer, A. E. G. Kr. von dem Borne, D. Roos, and P. A. T. Tetteroo. 1988. The PI-linked receptor FcRIII is released on stimulation of neutrophils. Nature (Lond.). 333:667-669.

25. Scallon, B. J., E. Scigliano, V. H. Freedman, M. C. Miedel, Y.-C. E. Pan, J. C. Unkeless, and J. P. Kochan. 1989. A human immunoglobulin $\mathrm{G}$ receptor exists in both polypeptide-anchored and phosphatidylinositol-glycan-anchored forms. Proc. Natl. Acad. Sci. USA. 86:5079-5083.

26. Ravetch, J. V., and B. Perussia. 1989. Alternative membrane forms of Fc $\gamma \mathrm{RIII}(\mathrm{CD} 16)$ on human natural killer cells and neutrophils. Cell type-specific expression of two genes that differ in single nucleotide substitutions. J. Exp. Med. 170:481-497. 